\title{
Antiretroviral Resistance and Genetic Diversity of Human Immunodeficiency Virus Type 1 Isolates from the Federal District, Central Brazil
}

\author{
Daniela M Cerqueira/ ++ , Regina MS Amorim, Ruiter R Silva*, Geni NL Camara**, \\ Marcelo M Brígido, Cláudia RF Martins/ ${ }^{+}$
}

\begin{abstract}
Pós-Graduação em Biologia Molecular, Instituto de Biologia, Universidade de Brasília, ICC Sul, 70919-900 Brasília, DF, Brasil
*Laboratório Central de Saúde Pública do Distrito Federal, Brasília, DF, Brasil **Agência Nacional de Vigilância Sanitária, Brasília, DF, Brasil
\end{abstract}

In the context of universal access to antiretroviral therapy, the surveillance of human immunodeficiency virus type 1 (HIV-1) genetic diversity and resistance becomes pivotal. In this work our purpose was to describe the genetic variability; prevalence of drug-resistance mutations; and genotypic resistance profiles in HIV-1 infected individuals under antiretroviral treatment, from the Federal District, Brasilia, Central Brazil. The entire viral protease and codons 19 to 234 of the reverse transcriptase gene from 45 HIV-1 isolates were amplified and sequenced for subtyping and genotyping. By phylogenetic analysis, $96 \%$ of the samples clustered with subtype B and the remaining $4 \%$ with HIV-1 subtype F sequences. One major protease inhibitor resistance-associated mutation, I5OV, was detected in $38 \%$ of the samples. Minor mutations were also found at the protease gene: L10I/V (7\%), K20M (2\%), M36I (11\%), L63P (20\%), A7IT (2\%), and V77I (7\%). Many mutations associated with reduced susceptibility to nucleoside or nonnucleoside reverse transcriptase inhibitors were detected: M41L (11\%), E44D (4\%), D67N (11\%), T69D (2\%), K70R (11\%), L74V (2\%), L100I (4\%), K103N (18\%), V118I (9\%), Y181C (11\%), M184V (18\%), G190A (4\%), T215Y (4\%), and K219E (4\%). This study has shown that $84 \%$ of the studied population from the Federal District, showing evidences of therapy failure, presented viral genomic mutations associated with drug resistance. The main antiretrovirals to which this population showed resistance were the PI amprenavir (38\%), the NNRTIs delavirdine, nevirapine (31\%), and efavirenz (24\%), and the NRTIs lamivudine (18\%), abacavir, and zidovudine (13\%).

Key words: human immunodeficiency virus type 1 (HIV-1) - genotyping - antiretroviral resistance - protease reverse transcriptase - Brazil

Human immunodeficiency virus type 1 (HIV-1) has been classified into nine group $M$ genetic subtypes: A-D, F-H, J, and K. Recombination between these subtypes has led to the generation of many circulating recombinant forms (CRF). Fifteen different CRFs have already been identified and may play a major role in local epidemics. These HIV-1 group M genetic forms account for most of HIV infections worldwide (Robertson et al. 1999, Thomson et al. 2002, Rambaut et al. 2004).

HIV-1 genetic forms may have variable biological properties and display different geographical prevalences, justifying the need for regional characterization and surveillance. The study of HIV-1 genetic variability in distinct regions of the world is also important in the design of more efficient HIV vaccines, which may include the circulating subtypes. Recent data indicate that viral subtypes may influence immune responses and the effectiveness

Financial support: Fundação de Empreendimentos Científicos e Tecnológicos

${ }^{+}$Corresponding author. Fax: +55-61-272.1793. E-mail: cmartins@unb.br

${ }^{++}$Fellowship from the Conselho Nacional de Desenvolvimento Científico e Tecnológico

Received 24 May 2004

Accepted 24 November 2004 of antiretroviral treatment (Thomson et al. 2002, Perrin et al. 2003).

To date, therapy options for the management of HIV-1 disease include 6 nucleoside and 1 nucleotide reverse transcriptase inhibitors (NRTI), 3 non-nucleoside reverse transcriptase inhibitors (NNRTI), and 7 PR inhibitors (PI). However, data have shown the emergence of HIV-1 drug resistance mutations in treated and untreated individuals (Hirsch et al. 2003, Shafer 2003).

The Brazilian Ministry of Health has been sponsoring free access to HIV treatment for AIDS patients since 1996 (Dumans et al. 2002, Tanuri et al. 2002). Nevertheless, the selection of viral resistant strains is a major problem for the medical management of infected individuals and accounts for the transmission of these variants to non-infected people. This represents an important public health problem, particularly in areas where antiretroviral drugs have been widely used for many years (Little et al. 2002, Hirsch et al. 2003).

A previous study has shown a low frequency of wild type isolates among treated patients from the Federal District in comparison with those from other Brazilian sites (Tanuri et al. 2002). Moreover, in a previous report we have found a high prevalence $(84.2 \%)$ of virus strains from Federal District samples collected at 1998 containing resistance mutations (Cerqueira et al. 2004). Here, we describe the genetic diversity of HIV-1 PR and RT sequences, as well as the genotypic resistance profiles of HIV-1 iso- 
lates from infected individuals under antiretroviral treatment, living in the Federal District, Central Brazil during the year of 2002 in order to monitor the prevalence of drug resistance mutations and genetic subtypes.

\section{MATERIALS AND METHODS}

Study population - The starting material was RNA previously extracted for viral load measurement. These HIV-1 RNA samples from 45 infected individuals were collected at a Public Health Laboratory located at the Federal District (Lacen-DF), in 2002. All samples belonged to individuals who had viral load counts higher than 100,000 copies $/ \mathrm{ml}$ and were under antiretroviral drug treatment. The viral load data were collected and patient identifying information was excluded from sample tubes. The Committee on Human Research Ethics granted prior approval to this research project.

RNA extraction and cDNA synthesis - Viral RNA was extracted from plasma samples using the Nucleon-HT Kit (Organon-Teknika) according to the manufacture's protocol, and stored at $-70^{\circ} \mathrm{C}$. Complementary DNA (cDNA) was synthesized from $5 \mu \mathrm{l}$ of extracted RNA using $2 \mathrm{U}$ of $M$ - $M u$ LV RT (Gibco) plus 0.2 mM dNTP, 2 U RNAse inhibitor (Pharmacia Biotech), and $0.5 \mu \mathrm{g}$ of random primer. The reaction condition was $37^{\circ} \mathrm{C}$ for $60 \mathrm{~min}$.

$R T$ and $P R$ gene amplification and sequencing - Two different HIV-1 genomic regions were targeted for polymerase chain reaction (PCR) amplification: PR and RT. The cDNA was used as template in a two-stage nested PCR amplification of the full-length PR gene and of a fragment corresponding to codons 19 to 234 of the RT gene, which harbors most of the known resistance mutations to licensed antiretroviral drugs. PR gene amplification used the outer primers DP10/DP11 $(20 \mathrm{nM})(\mathrm{Gibco})$ and the inner primers DP16/DP17 (20 nM) (Gibco) (Brasil 1999). To amplify the fragment of the RT gene, we used the outer primers RT09/RT12 (20 nM) (Gibco) and the inner primers RT01/RT04 (20 nM) (Gibco) (Brasil 1999). PCR was carried out in $10 \mathrm{mM}$ Tris-HCL (pH 8.3) (Life Technologies, Gibco), $50 \mathrm{mM} \mathrm{KCl}$ (Sigma Chemicae Co.), $1.5 \mathrm{mM} \mathrm{MgCl}_{2}$ (Life Technologies, Gibco), $0.2 \mathrm{mM}$ each dNTP(Gibco), $0.8 \mu \mathrm{M}$ each primer, $2 \mathrm{U}$ Taq polymerase (Gibco), and $5 \mu \mathrm{l}$ cDNA solution. An aliquot $(1 \mu \mathrm{l})$ of the primary PCR product was used for nested PCR in the same conditions. The PR amplification gave a 297-bp product and, the RT amplification, a 647-bp product.

The PCR products were subjected to direct population sequencing of both strands, using the inner PCR primer set. Nucleotide sequences were determined automatically by the dideoxy chain termination method, in a Megabace System (Amersham-Pharmacia). Sequence edition and alignments were performed using the CLUSTAL $\mathrm{W}$ multiple-sequence alignment program (Thompson et al. 1994). Minor manual adjustments were made to improve the alignments.

Genotyping - The aligned DNA sequences were translated into amino acids and mutations were defined as differences from the HIV-1 consensus subtype B sequence (available at: http://www.hiv.lanl.gov/content/hiv-db/ CONSENSUS). Information on mutations associated with resistance was obtained from the International AIDS Society-USA (IASUSA) guidelines (Johnson et al. 2003).
Interpretation of genotypic data was performed by HIVdb program at the HIV RT and PR Sequence Database (http:/ /hivdb.stanford.edu) (Rhee et al. 2003). This is a computerized rules-based algorithm that provides the similarity of user-submitted sequences with the closest subtype reference sequence and classifies the virus as "susceptible", "possible resistant", or "resistant" to each antiretroviral agent. In the PR gene, resistance mutations were classified as major or minor, according to recommendations of IASUSA (Johnson et al. 2003).

Phylogenetic analysis - For each HIV-1 isolate, PR and RT sequences were grouped. The resulting sequences were aligned with reference sequences of various subtypes from the Los Alamos HIV database (http://hivweb.lanl.gov), using CLUSTAL W program. Phylogenetic analysis was performed by the neighbor-joining distance method with Kimura's two-parameter correction (Kimura 1980), by using PHYLIP package (Felsenstein 1993). The SIVCPZ PR and RT sequences were also grouped and used as outgroup for phylogenetic comparisons. Tree was drawn using TREE-VIEW program and the reliability of the branching orders was estimated by the bootstrap approach (1000 replicates).

Sequences that did not branched with the reference subtypes were analyzed by SimPlot version 2.5 program (Ray 1999).

\section{RESULTS}

All 45 samples were successfully amplified in PR and RT regions. Based on pol PR and RT sequence, most of our isolates $(n=43.96 \%)$ clustered phylogenetically with subtype B reference sequences. The sequences of isolates DF02.14 and DF02.40 (4\%) formed a separate branch (Fig. 1) and were analyzed by SimPlot program, which suggested the occurrence of PR B/RT F recombinants (data not shown).

The distribution of HIV-1 resistance-associated mutations in the PR and RT genes is shown in Fig. 2. At PR sequences, only one major mutation, I50V, was detected in 17 sequences $(38 \%)$. Minor mutations were seen at positions L10I/V (7\%), K20M (2\%), M36I (11\%), L63P (20\%), A71T (2\%), and V77I (7\%), but occurred at low frequencies, with the exception of those at positions 36 and 63 (Fig. 2A).

The distribution of known resistance mutations in RT sequences was as follows: M41L (11\%), E44D (4\%), D67N (11\%), T69D (2\%), K70R (11\%), L74V (2\%), V118I (9\%), M184V (18\%), T215Y (4\%), and K219E (4\%), which are associated to NRTI resistance, and L100I (4\%), K103N $(18 \%), \mathrm{Y} 181 \mathrm{C}(11 \%)$, and G190A (4\%), which are associated to NNRTI resistance (Fig. 2B).

In addition to the resistance-associated mutations found within the PR and RT regions, many other polymorphisms were detected (data not shown). These amino acid variants at polymorphic positions do not cause drug resistance by themselves and emerge as genetics variants with apparently equivalent replication capacity (Holguín et al. 2002). At the PR gene, the most frequent polymorphism occurred at codon N37 (67\%) and, at the RT gene, $58 \%$ of the genotypes showed polymorphism at codon $\mathrm{I} 135$. 
In total, $84 \%$ of HIV-1 infected subjects from the Federal District presented viral genomic mutations associated with drug resistance. Mutations associated with PI resistance were found at $73 \%$ of the viral sequences and those associated with RTI resistance at $42 \%$. Among these sequences containing RTI resistance-associated mutations, $36 \%$ was associated with NRTI resistance and $31 \%$ with NNRTI resistance.

The inferred levels of resistance were deduced from the amino acid sequences. To each sample, the PR and RT regions were classified in one of the following levels of drug resistance: susceptible, intermediate resistance or resistant. Of the 45 samples, $62 \%$ showed resistance to at least one of the antiretrovirals analyzed. Sixteen patients

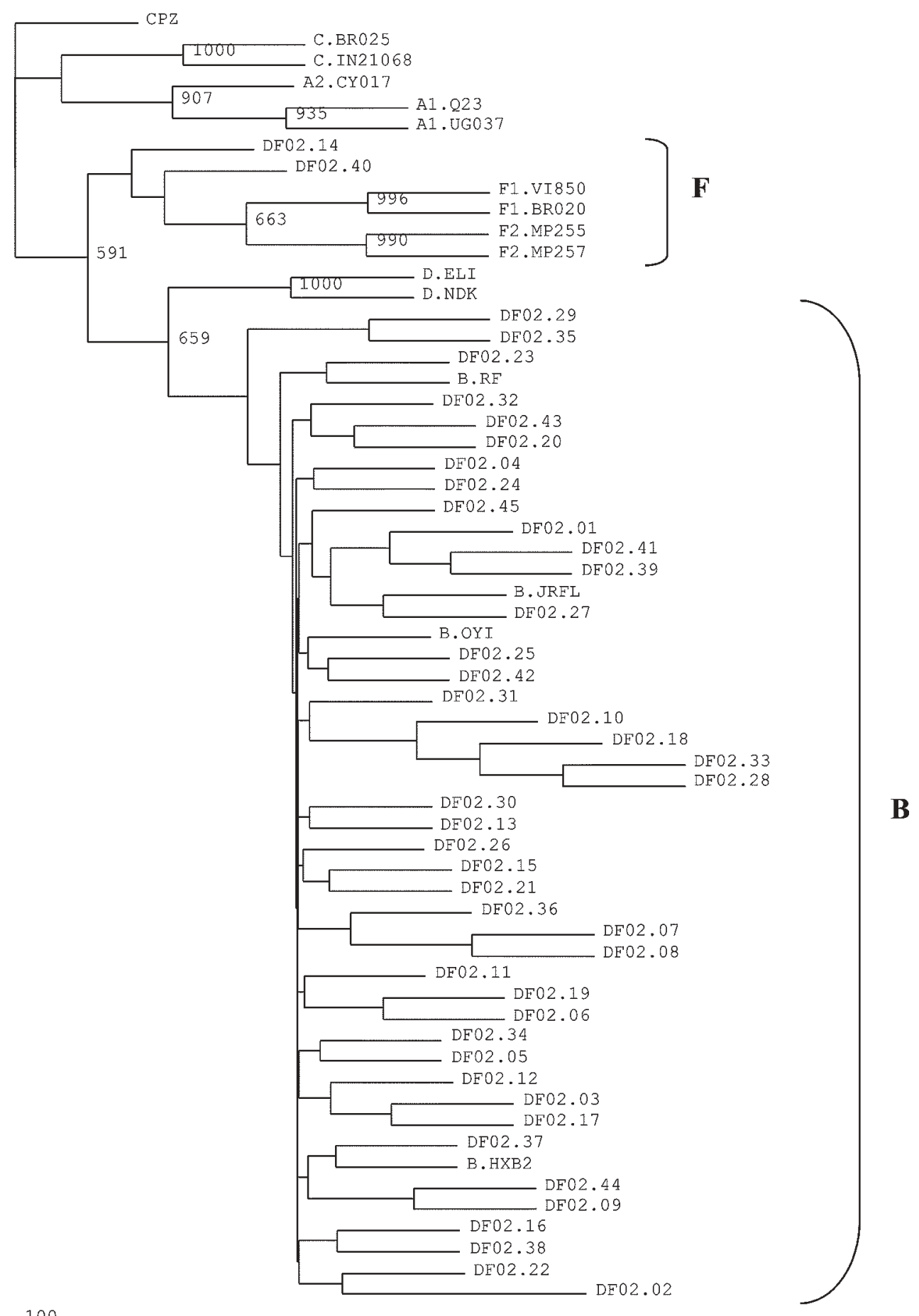

100

Fig. 1: neighbor-joining protease and reverse transcriptase tree including all specimens sequenced (DF02.n) and indicating the putative subtype of each isolate. Reference sequences for A, B, C, D, and F clades from the Los Alamos database were also included. The Kimura twoparameter method of estimating genetic distances was used. Numbers next to the nodes of the tree represent bootstrap values (1000 replicates). 

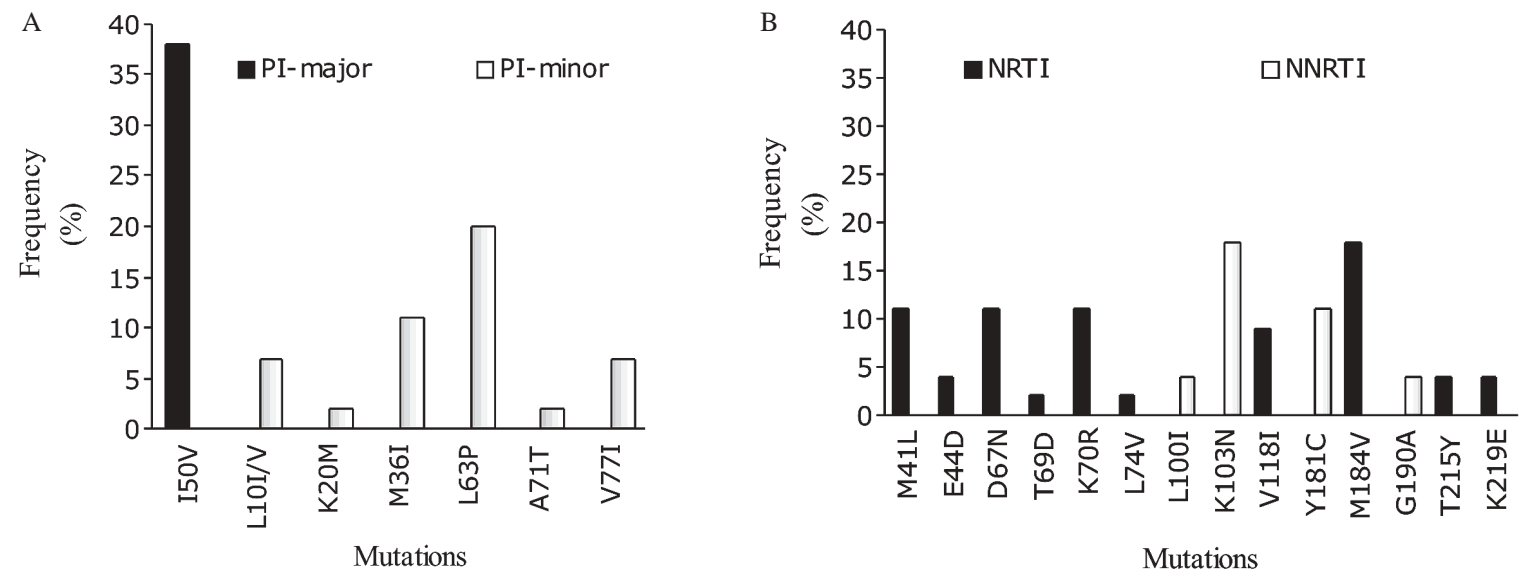

Fig. 2: percentages of protease sequences with protease inhibitors (PI)-associated major and minor mutations (A) and of reverse transcriptase (RT) sequences with nucleoside RT (NRTI) and non-nucleoside RT (NNRTI) inhibitor-associated resistance mutations (B).

(36\%) carried viruses predicted to be susceptible to all PI, NRTI, and NNRTI. No patients had viruses classified as resistant to all of these drugs. Viruses that were predicted to be sensitive to all PI were found in $62 \%$, to all NRTI in $64 \%$, and to all NNRTI in $69 \%$ of the individuals studied here (Fig. 3).

The highest level of resistance was observed to amprenavir (APV) (38\%), the only PI to which resistant samples were detected. Viruses classified as resistant to all NNRTI were found in $24 \%$ of the samples, whereas those resistant only to delavirdine (DLV) and nevirapine (NVP) were detected at a higher frequency $(31 \%)$. For NRTIs, the frequencies of resistant isolates varied from $18 \%$ (lamivudine - 3TC) to $2 \%$ (tenofovir - TDF) (Fig. 3). The high percentages of samples resistant to NNRTI ob- served on Fig. 3 were not previously described at the Federal District, as samples from 1998 were classified as susceptible to all drugs of this class (Cerqueira et al. 1994).

\section{DISCUSSION}

Several recent reports have shown that the numerous selection pressures on the pol gene make it suitable for phylogenetic studies (Njouom et al. 2003). HIV-1 subtypes were determined here by sequencing the PR and RT genes of plasma viruses, an approach that has proved to be useful by other investigators (Ramos et al. 1999, Holguín et al. 2002). PR and RT sequences were grouped because phylogenetic analysis of PR sequences appears to be less trustworthy than that of RT. This is probably due to the size of the PR gene, which has fewer variations among

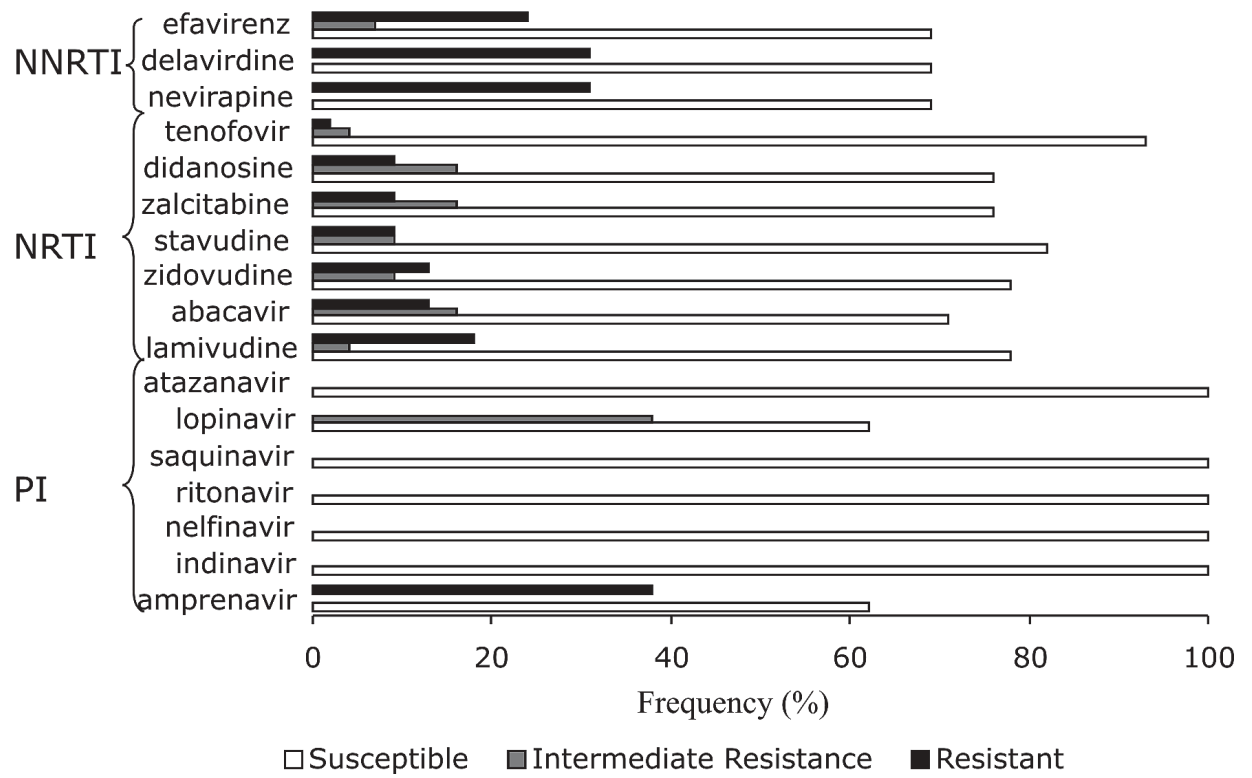

Fig. 3: frequencies of resistance levels to non-nucleoside (NNRTI) and nucleoside (NRTI) reverse transcriptase inhibtors and to protease inhibitors. The horizontal bars indicates the frequencies of susceptible, intermediate resistance, and resistant samples to NNRTIs and NRTI reverse transcriptase inhibitors and to PI. 
subtypes and less phylogenetically informative sites. Moreover, the analysis of the PR sequences alone may be doubtful due to closely-related subtypes or recombinant viruses (Gonzales et al. 2001, Pasquier et al. 2001).

Brazil is a huge country and differences in the pattern of HIV-1 subtypes distribution have been identified among the geographic regions. Thus it is important to monitor subtype profiles, as their distribution has local determinants, and data from one site cannot be generalized for the entire country or even for a single geographic region. HIV-1 subtype B is the most prevalent in our country, followed by subtype F1, with sporadic cases of subtypes C, D, and A (Rossini et al. 2001, Morgado et al. 2002, Tanuri et al. 2002, Gadelha et al. 2003, Soares et al. 2003).

We performed the HIV-1 genetic subtyping on 45 samples from the Federal District, based on phylogenetic analysis of the PR and RT genes. Our results reflect subtypes distribution previously observed in other Brazilian regions, as subtype B was the most prevalent (96\%). The remaining two samples $(4 \%)$ seem to be recombinants between subtypes B and F, what has also been described in Brazil and may explain why they do not branch with the reference samples in the phylogenetic tree (Ramos et al. 1999, Gadelha et al. 2003, Cerqueira et al. 2004). Studies are being conducted in order to analyze subtype homologies of these samples based on additional genes.

Eighty four percent of the HIV-1 infected studied subjects from the Federal District, who were under antiretroviral treatment and with viral load counts higher than 100,000 copies/ml, presented viral genomic mutations associated with drug resistance. This result is close to that reported in another Brazilian study, where $84.7 \%$ of the virus strains showed resistance-associated mutations (Tanuri et al. 2002) and to the frequency of $84.2 \%$ that we have found on samples collected at 1998 (Cerqueira et al. 2004).

The higher prevalence of resistance mutations in the $\mathrm{PR}$ region, when compared to $\mathrm{RT}$, could be associated with extensive use of PI for the treatment of infected individuals in the Federal District. This may be particularly true for APV, as this PI-associated major mutation, I50V, was found in $38 \%$ of the subjects analyzed. Alternatively, I50V may represent a signature of HIV-1 strains from the Federal District. This calls for further investigation, already in course.

PR minor mutations were observed at low frequencies ( 2 to $11 \%$ ), with the exception of L63P, which was detected at $20 \%$ of PR sequences. Position 63 is the most polymorphic codon of the PR, which may explain this result (Rhee et al. 2003). The detection of PR minor mutations at $36 \%$ of the samples is of concern since these mutations can reduce the genetic barrier and yield a faster selection of resistant strains when compared to wild type isolates (Brindeiro et al. 2003).

At the RT gene, K103N was the most frequent (18\%) NNRTI-associated mutation, which agrees with data reporting that this mutation occurs more commonly than any other mutation in patients receiving NNRTI and may cause resistance to each one of them (Shafer 2002). Amino acid substitutions at codon 135 were detected at a high frequency $(58 \%)$. This position comprises one of the three mutations that have recently been identified as novel sites that may influence susceptibility to NNRTI (Magiorkinis et al. 2002, Shafer 2003).

Sixty-two percent of patients under antiretroviral therapy and with high viral load counts (> 100,000 copies/ $\mathrm{ml}$ ) showed resistance to at least one of the antiretrovirals analyzed. This result is probably related to antiretroviral drug treatment selective pressure and suggests that these patients were not responding to antiretroviral therapy, underling the necessity of their monitoring with regard to the possibility of changing current regimens. For 1998 samples, a similar rate (58\%) of resistance to at least one antiretroviral was observed (Cerqueira et al. 2004).

Only $36 \%$ of the sequences were classified as susceptible to all antiretroviral drugs. Of great importance was the high level of resistance to the PI amprenavir (38\%), and to the NNRTI delavirdine and nevirapine (31\%). This might result from the fact that a single mutation may cause high-level resistance to NNRTI(s) and may also reflect the high level of cross resistance among these drugs, as well as their wide use in the Federal District (Shafer 2002).

It is interesting to note that mutations associated to NNRTI resistance were not previously found in the Federal District (Cerqueira et al. 2004). However, $24 \%$ of the samples analyzed here were classified as resistant to all NNRTI and, among RT inhibitors, the highest levels of resistance were observed to the non-nucleoside ones (Fig. $3)$. These results suggest the selection of NNRTI resistant strains due to the pressure of these drugs after their introduction in the Federal District. We might also speculate that a significant increase on resistance is expected as these drugs become more used on antiretroviral treatments.

The knowledge of resistance profiles of virus strains from each locality may be helpful to guide the treatment of HIV infected individuals, reducing effective public health costs. It is particularly important for São Paulo and Brasília, where antiretroviral drugs were first made available and probably the patients of these sites are exposed to anti-HIV therapy longer than people from other sites. Drug pressure could have driven the selection of resistant strains and may put at risk the efforts in controlling AIDS morbidity and mortality by antiretroviral therapy. Moreover, these drug resistant strains can be transmitted to non-infected individuals, contributing to a spread of resistance among the Brazilian population (Brenner et al. 2000, Little et al. 2002, Tanuri et al. 2002, Hirsch et al. 2003).

\section{ACKNOWLEDGEMENTS}

To John Penney, for reviewing this manuscript.

\section{REFERENCES}

Brasil 1999. Ministério da Saúde, Coordenação Nacional de DST e AIDS, Projeto piloto de monitoramento da resistência do HIV-1 aos anti-retrovirais. Apostila e protocolos do curso de genotipagem rápida do HIV-1.

Brenner B, Wainberg MA, Salomon H, Rouleau D, Dascal A, Spira B, Sekaly R-P, Conway B, Routy J-P, Investigators of the Quebec Primary Infection Study 2000. Resistance to antiretroviral drugs in patients with primary HIV-1 infection. Int J Antimicrob Agents 16: 429-434.

Brindeiro PA, Brindeiro RM, Mortensen C, Hertogs K, De 
Vroey V, Rubini NP, Sion FS, De Sa CA, Machado DM, Succi RC, Tanuri A 2002. Testing genotypic and phenotypic resistance in human immunodeficiency virus type 1 isolates of clade B and other clades from children failing antiretroviral therapy. J Clin Microbiol 40: 4512-4519.

Cerqueira DM, Ramalho ED, Oliveira CP, Silva RR, Franchini M, Felipe MSS, Martins CRF 2004. HIV-1 subtypes and mutations associated to antiretroviral drug resistance in human isolates from Central Brazil. Braz. J Microbiol 35, accepted.

Dumans AT, Soares MA, Pieniazek D, Kalish ML, De Vroey V, Hertogs K, Tanuri A 2002. Prevalence of protease and reverse transcriptase drug resistance mutations over time in drug-naïve human immunodeficiency virus type 1-positive individuals in Rio de Janeiro, Brazil. Antimicrob Agents Chemother 46: 3075-3079.

Felsenstein J 1993. PHYLIP (Phylogeny Inference Package) version 3.5c. Distributed by the author. Department of Genetics, University of Washington, Seattle.

Gadelha SR, Shindo N, Cruz JNM, Morgado MG, GalvãoCastro B 2003. Molecular epidemiology of human immunodeficiency virus-1 in the state of Ceará, Northeast, Brazil. Mem Inst Oswaldo Cruz 98: 461-464.

Gonzales MJ, Machekano RN, Shafer RW 2001. Human immunodeficiency virus type 1 reverse-transcriptase and protease subtypes: classification, amino acid mutation patterns, and prevalence in a Northern California clinic-based population. J Infect Dis 184: 998-1006.

Hirsch MS, Brun-Vézinet F, Clotet B, Conway B, Kruitzkes DR, D'Aquila RT, Demeter LM, Hammer SM, Johnson VA, Loveday C, Mellors JW, Jacobsen DM, Richman DD 2003. Antiretroviral drug resistance testing in adults infected with human immunodeficiency virus type 1: 2003 recommendations of an International AIDS Society-USA Panel. Clin Infect Dis 37: 113-28.

Holguín A, Álvarez A, Soriano V 2002. High prevalence of HIV-1 subtype G and natural polymorphisms at the protease gene among HIV-infected immigrants in Madrid. AIDS 16: $1163-1170$

Johnson VA, Brun-Vézinet F, Clotet B, Conway B, D'Aquila RT, Demeter LM, Kuritzkes DR, Pillay D, Schapiro JM, Telenti A, Richman DD, International AIDS Society-USA Drug Resistance Mutations Group 2003. Drug resistance mutations in HIV-1. Topics in HIV Medicine 11: 215-221.

Little SJ, Holte S, Routy J-P, Daar ES, Markowitz M, Collier AC, Koup RA, Mellors JW, Connick E, Conway B, Kilby M, Wang L, Whitcomb JM, Hellmann NS, Richman DD 2002. Antiretroviral-drug resistance among patients recently infected with HIV. N Engl J Med 347: 385-394.

Kimura M 1980. A simple method for estimating evolutionary rates of base substitutions through comparative studies of nucleotide sequence. J Mol Evol 16: 111-120.

Magiorkinis E, Paraskevis D, Magiorkinis G, Chryssou S, Chini M, Lazanas M, Paparizos V, Saroglou G, Antoniadou A, Giamarellou E, Karafoulidou A, Hatzakis A 2002. Mutations associated with genotypic resistance to antiretroviral therapy in treatment naïve HIV-1 infected patients in Greece. Virus Res 85: 109-115.

Morgado MG, Guimarães ML, Galvão-Castro B 2002. HIV-1 polymorphism: a challenge for vaccine development - A review. Mem Inst Oswaldo Cruz 97: 143-150.

Njouom R, Pasquier C, Sandres-Sauné K, Harter A, Souyris C,
Izopet $\mathbf{J}$ 2003. Assessment of HIV-1 subtyping for Cameroon strains using phylogenetic analysis of pol gene sequences. J Virol Meth 110: 1-8.

Pasquier C, Millot N, Njouom R, Sandres K, Cazabat M, Puel J, Izopet J 2001. HIV-1 subtyping using phylogenetic analysis of pol gene sequences. 2001. J Virol Meth 94: 45-54.

Perrin L, Kaiser L, Yerly S 2003. Travel and the spread of HIV1 genetic variants. Lancet Infect Dis 3: 22-27.

Rambaut A, Posada D, Crandall KA, Holmes EC 2004. The causes and consequences of HIV evolution. Nature Reviews 5: 52-61.

Ramos A, Tanuri A, Schechter M, Rayfield MA, Hu DJ, Cabral MC, Bandea CI, Baggs J, Pieniazek D 1999. Dual and recombinant infections: an integral part of the HIV-1 epidemic in Brazil. Emerg Infect Dis 5: 65-74.

Ray SC 1999. SimPlot for Windows (version 2.5). Baltimore, MD. Distributed by author. Available at http:// sray.med.som.jhmi.edu/RaySoft/SimPlot/.

Rhee S-Y, Gonzales MJ, Kantor R, Betts BJ, Ravela J, Shafer RW 2003. Human immunodeficiency virus reverse transcriptase and protease sequence database. Nucleic Acids Res 31: 298-303.

Robertson DL, Anderson JP, Bradac JA, Carr JK, Foley B, Funkhouser RK, Gao F, Hahn BH, Kalish ML, Kuiken C, Learn GH, Leitner T, McCutchan F, Osmanov S, Peeters M, Pieniazek D, Salminen M, Sharp PM, Wolinsky S, Korber B 1999. HIV-1 nomenclature proposal. In CL Kuiken, B Foley, B Hahn, B Korber, F McCutchan, PA Marx, JW Mellors, JI Mullins, J Sodroski, S Wolinksy 1999. Human Retroviruses and AIDS 1999: a Compilation and Analysis of Nucleic Acid and Amino Acid Sequences, Theoretical Biology and Biophysics Group, Los Alamos National Laboratory, Los Alamos, p. 492-505.

Rossini MAA, Diaz RS, Caseiro M, Turcato G, Accetturi CA, Sabino EC 2001. HIV-1 subtypes among intravenous drug users from two neighboring cities in São Paulo State, Brazil. Braz, J Med Biol Res 34: 45-47.

Shafer RW 2002. Genotypic testing for human immunodeficiency virus type 1 drug resistance. Clin Microbiol Rev 15: 247-277.

Shafer RW 2003. Genotypic testing for HIV-1 drug resistance. Available at http://hivdb.stanford.edu.

Soares EAJM, Santos RP, Pellegrini JA, Sprinz E, Tanuri A, Soares MA 2003. Epidemiologic and molecular characterization of human immunodeficiency virus type 1 in Southern Brazil. J AIDS 34: 520-526.

Tanuri A, Caridea E, Dantas MC, Morgado MG, Mello DL, Borges S, Tavares M, Ferreira SB, Santoro-Lopes G, Martins CR, Esteves AL, Diaz RS, Andreo SM, Ferreira LA, Rodrigues R, Reuter T, Cavalcanti AM, de Oliveira SM, de Barbosa HB, Teixeira PR, Chequer PN 2002. Prevalence of mutations related to HIV-1 antiretroviral resistance in Brazilian patients failing HAART. J Clin Virol 25: 39-46.

Thompson J, Higgins D, Gibson T 1994. CUSTAL W: improving the sensitivity of progressive multiple sequence alignment through sequence weighting, position-specific gap penalties and weight matrix choice. Nucleic Acid Res 22: 4673-4680.

Thomson MM, Pérez-Álvarez L, Nájera R 2002. Molecular epidemiology of HIV-1 genetic forms and its significance for vaccine development and therapy. Lancet Infect Dis 2: 461-471. 